\title{
PATTERNS OF FACIAL FRACTURES TREATED IN FACULTY OF DENTISTRY (CAIRO UNIVERSITY) HOSPITAL: A RETROSPECTIVE STUDY
}

\author{
Ahmed T. Elsharkawy*, Amira A. Zaied**, Heba M. Kamel* and Sayed A. Rashed***
}

\begin{abstract}
Background: The epidemiology of facial injuries varies based on lifestyle, cultural background and socioeconomic status in different countries and geographic zones. Facial fractures can lead to significant functional and aesthetic sequelae if treated improperly. Thus, knowledge of mandibular fracture epidemiology is important to guide the preventive efforts of the Egyptian health care system.
\end{abstract}

Aim: The aim of this study was to review the patterns of facial fractures among patients treated in the Faculty of Dentistry, Cairo University.

Methods: Patients treated at General anesthesia Units, Faculty of Dentistry, Cairo University during a three years period (between 2016 and 2018) were retrospectively evaluated regarding age, gender, etiology, number of fractures pattern of fractures, and treatment methods.

Results: A total of 324 patients were treated during that period, $85 \%$ of them were males and $15 \%$ females. Most common age was the $3^{\text {rd }}$ decade and the least was the $7^{\text {th }}$. Road traffic accidents RTA was the most common etiology, followed by falls, assaults, and the least was animal hits and iatrogenic accidents. Most common fracture site was Parasymphysial, followed by angle, sub condylar, body, zygomatico-maxillary complex ZMC, Le Fort, orbital floor, and zygomatic arch respectively. $72 \%$ of fractures were treated by open reduction \& internal fixation ORIF while only $28 \%$ were treated by closed reduction.

Conclusion: RTAs are the most common cause of facial fracture among Cairo population; rules should be more strict regarding safety measures especially among Toktok and motorcycle drivers. The high number of patients treated in the faculty of dentistry hospital in spite of the presence of just two operation rooms, and the fact that most of the patients were treated by ORIF indicates that Oral and Maxillofacial Surgery department staff members are active and well trained.

KEYWORDS: Facial Fractures, Mandibular fractures, Retrospective study, Young and adult patient, Cairo University.

* Department of Oral and Maxillofacial Surgery, Faculty of Dentistry, Cairo University, Egypt

** Department of Oral and Maxillofacial Surgery, Faculty of Dentistry, Fayoum University, Egypt

*** Department of Oral and Maxillofacial Surgery, Faculty of Dentistry, Ahram Canadian University, Egypt 


\section{INTRODUCTION}

The maxillofacial fractures are one of the most common traumatic injuries in the society ${ }^{1}$; the patterns and mechanisms of injury and the distribution within a given population vary considerably among study groups ${ }^{2}$. Furthermore, there is no consensus among prior landmark studies regarding the epidemiology and demographics of maxillofacial fractures in Egypt. This lack of consensus seems to be a reflection of epidemiologic and demographic variability among reporting trauma centers ${ }^{3-6}$. As such, extrapolation of existing data might not be an accurate representation of national patterns, but it represents one of the most public and central facial traumas in Egyptian society, as maxillofacial injuries occur in a significant proportion of trauma patients. Trauma causes considerable economic expense due to procedural costs, the time a patient is off work, and the associated loss of income. For these reasons, it is an important health and economic issue ${ }^{7}$.

The purpose of this study was to provide an updated epidemiologic and demographic report on the considerable sample of maxillofacial fractures reported by data collection from the Patients data who were treated at General anesthesia Units, Faculty of Dentistry, Cairo University during a three years period (between 2016 and 2018) where they were retrospectively evaluated regarding age, gender, etiology, number of fractures, location of fractures, and treatment methods.

The hypothesis was that differences in demographic factors, such as age and gender, would be associated with different mechanisms of injury and anatomic locations of the fracture. . A better understanding of the influence of age and gender on the mechanism of injury and the anatomic site is of great clinical importance in the assessment, diagnosis, and treatment of traumatic maxillofacial fractures. Especially the period of our study (20162018) in Cairo as capital city within center of Egypt is reflecting the demographic status in the society as balanced regular area representing casual every day life cycle

\section{MATERIAL AND METHODS}

A retrospective review of all facial fractures treated at the faculty of dentistry, Cairo University hospitals over a three years period (From 2016 to 2018) was performed. The Hospital Managing Board approved this study.

All medical reports were examined to obtain the following data: Patient gender, age, etiology of fracture, number and location of fractures, and finally date and technique of treatment.

Patients were categorized into 7 age groups, where a group represented each decade.

Injury etiology was classified as Road Traffic accidents (RTA), Violence (fights or assaults), Animal Kicks, Falls, and Iatrogenic (during surgical extraction).

Numbers of fractures were either single, double, triple or multiple, and fracture location was categorized as Parasymphysial, body, angle, condylar, Le Fort, Zygomaticomaxillary complex fractures (ZMC), orbital rim and zygomatic arch fractures.

Treatment technique was either; Open reduction and internal fixation using plates and screws (ORIF) (with or without grafting) or Closed reduction using a split acrylic splint, or intermaxillary fixation (IMF).

Data was summarized, and results were calculated using Microsoft Excel 2017

\section{RESULTS}

A total of 324 patients were treated during that period, $85 \%$ of them were males and $15 \%$ females. Most common age was the $3^{\text {rd }}$ (124 patients), followed by $2^{\text {nd }}$ decade (82), then $4^{\text {th }}$ decade (59), $1^{\text {st }}$ decade (27), then $5^{\text {th }}$ and $6^{\text {th }}(15 \& 12$ patients) and the least was the $7^{\text {th }}$ decade age group with only 5 patients (Figure 1).

Regarding etiology of fracture; Road traffic accidents (RTA) was the leading cause with 176 cases, followed by falls and fights (68 \& 55), 
then being hit by a hard object ( 9 cases), and finally iatrogenic fractures during surgical extraction and being hit by animal with 7 cases each (Figure 2).

Most of the fractures (72\%) were treated by ORIF while only (28\%) were treated by closed reduction, mostly for the younger age group.

Most common fracture site was Parasymphysial (32.2\%), followed by angle fractures (17.6\%), subcondylar (16.7\%), mandibular body fractures (16.4\%), ZMC (8.2\%), Le Fort (4.1\%), orbital floor fractures $(2.9 \%)$, and zygomatic arch $(1.75 \%)$ respectively (Figure 3).

Regarding the relation between etiology of fracture and its location, we found that most of the

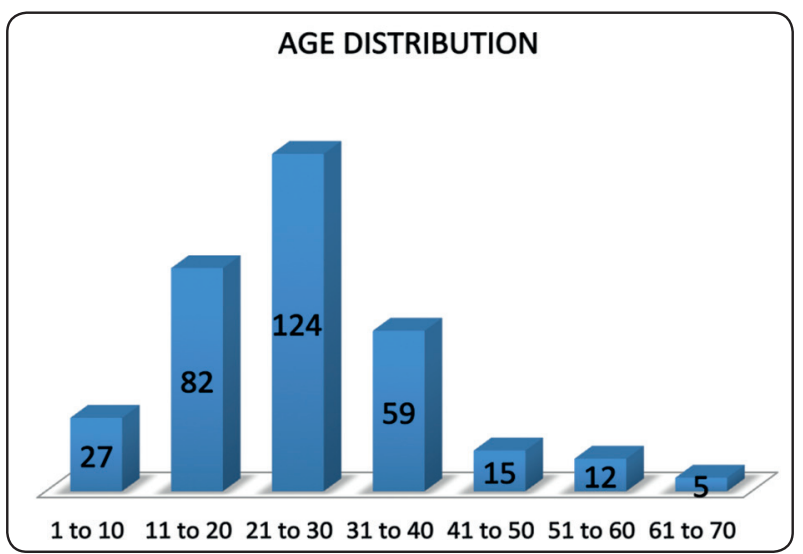

Fig. (1) Bar chart representing age distribution of trauma patients
RTA lead to Parasymphysial fractures, followed by angle fracture, then body and sub condylar with close percentage, then ZMC, Lefort 1, Orbital rim, and zygomatic arch respectively (Figure 4). While falls lead mostly to Parasymphysial fractures, then sub condylar and body fractures, and rarely to other types of fractures (Figure 5). Assaults lead mainly to Parasymphysial and body fractures, then angle, sub condylar and ZMC fractures, and least likely to cause other types (Figure 6).

Number of fracture lines was found to be: 176 patients had single fracture line, 106 patients had 2 fracture lines, 29 had 3, and 12 had more than 3 fracture lines (Figure 7).

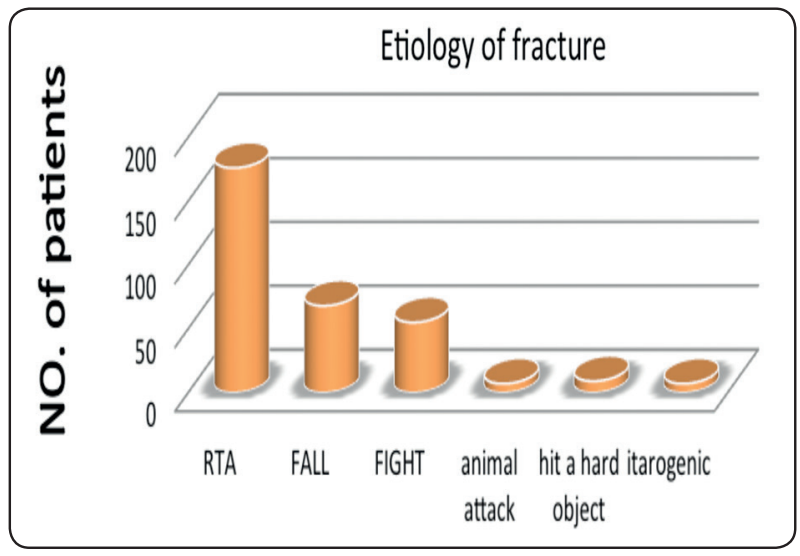

Fig. (2) Bar chart representing etiology of fracture distribution among trauma patients

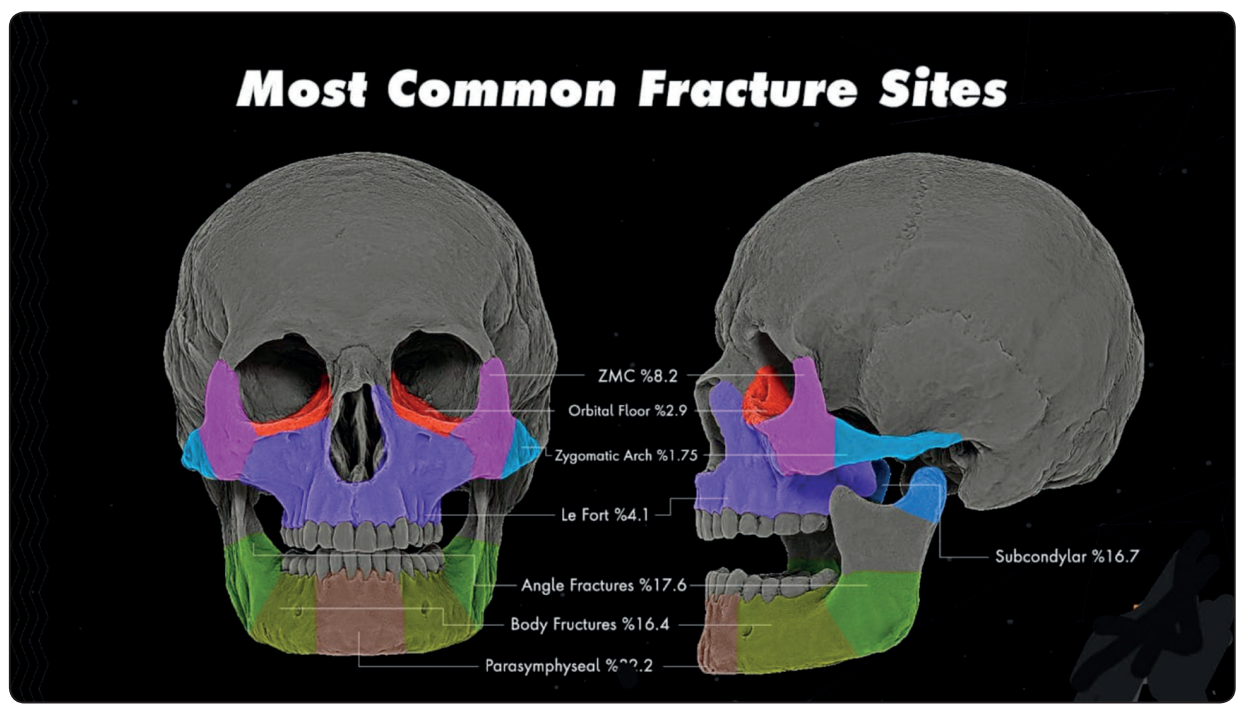

Fig. (3) Anatomic distribution of Facial fracture patterns 


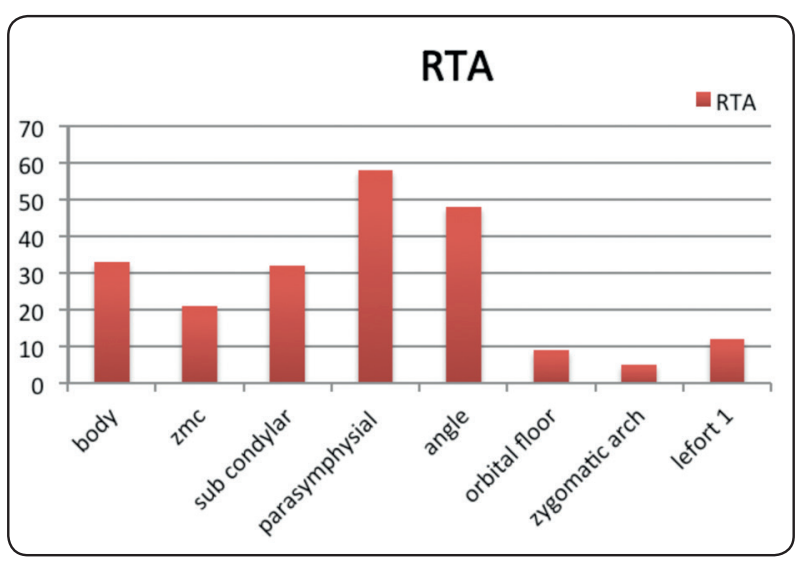

Fig. (4) Bar chart representing the number of each fracture pattern and the RTA group

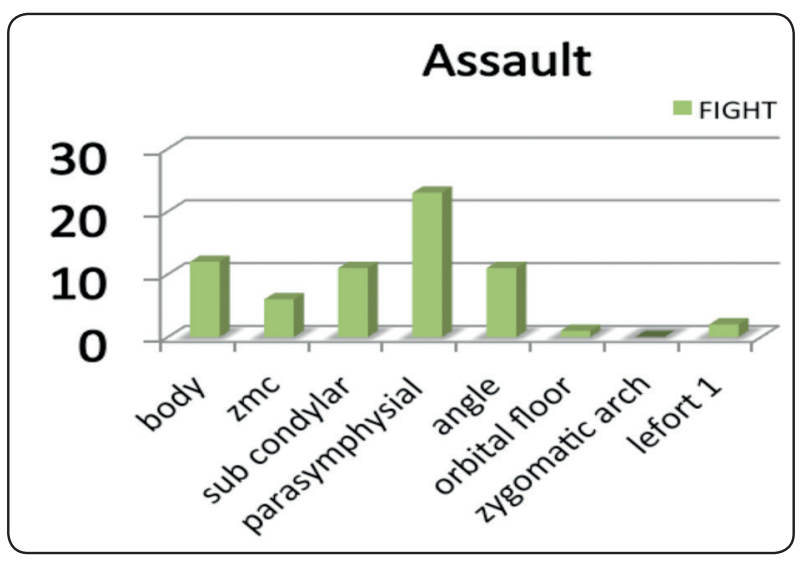

Fig. (6) Bar chart representing the number of fracture pattern and the Assault group

\section{DISCUSSION}

The total number of trauma patients treated at faculty of dentistry (Cairo University) hospitals general anesthesia units at the past 3 years was 324, this is the highest number of trauma patient reported among other similar studies at other national university hospitals as Ain Shams ${ }^{3}$, Alexandria ${ }^{4}$ and Sohag ${ }^{6}$, and also three of the governmental hospitals ${ }^{5}$. This is a promising fact; Knowing that the hospital is relatively new and that it includes only 2 Operating room. The large number of patients and the fact that most of them were treated by ORIF is perhaps due to the presence of large number of active, well trained, highly skilled surgeons at

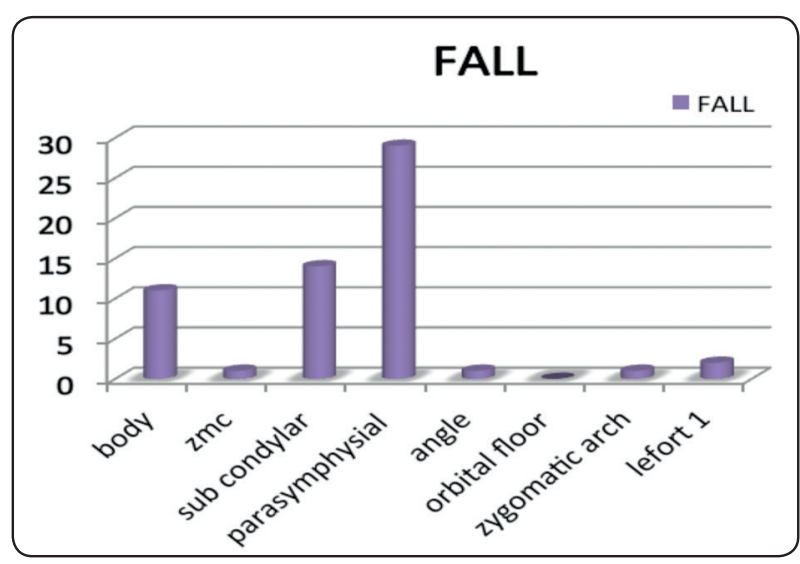

Fig. (5) Bar chart representing the number of each fracture pattern and the Fall group

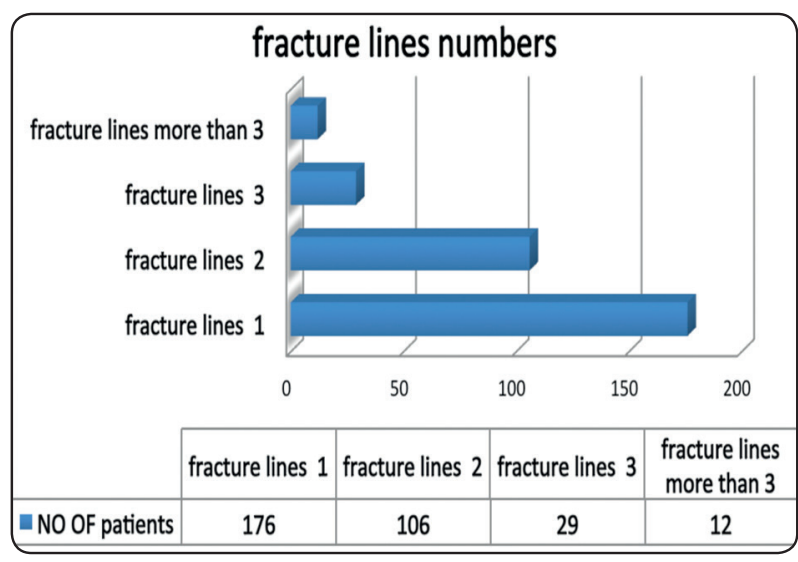

Fig. (7) Bar chart showing the number of fracture sites

Oral and Maxillofacial surgery department, faculty of dentistry, Cairo University, in addition to the previous good reputation of the other departments of El-Kasr El-Ainy hospital among Egyptians

Most of the patients included in this study were males; This is consistent with nearly all the similar universal studies, yet the ratio is different, with a ratio of nearly 5:1 in Cairo and Alexandria Universities ${ }^{4}$, it was $24: 1$ at Sohag University hospital ${ }^{6}$, This can be explained by the fact that women in upper Egypt rarely leave their houses, drive, do sports, or get subjected to violence. The ratio was similar in similar countries as it was 4.4:1 in Turkey ${ }^{8}, 5: 1$ in Venezuela ${ }^{9}$. However; the ratio 
was less in advanced countries as it was $2.7: 1$ in Switzerland ${ }^{10}$, perhaps due to the nearly equal duties and rights between both genders.

The peak age of maxillofacial fractures in this study was the $3^{\text {rd }}$ decade followed by the $2^{\text {nd }}$. This is consistent with nearly all the other studies ${ }^{1-17}$. This can be explained by the fact that this is the age of hard work, the age of professional sports practice, the age of reckless driving under the influence of drugs and alcohols. While the younger age group is protected by their elder watching over them, by their elastic bone and other favorable anatomic facts, and the older group are protected by their wisdom during movement and driving.

Most of the patients in this study were treated by means of ORIF using plates and screws (72\%), and most of those treated by closed reduction were the child age group in which ORIF is contraindicated. It's unknown if this is due to the increased number of well trained and skilled surgeons, or due to the fact that most of the IMF cases are treated under local anesthesia and they were not included in the same archive of data.

Regarding etiology of fracture among patients of this study, RTAs was found to be the leading cause of fracture with the percentage of $54.3 \%$. This is consistent with similar studies at similar countries; for example, it was $82 \%$ in Taiwan ${ }^{12}, 85 \%$ in India ${ }^{13}$ and $79.2 \%$ at another study in India ${ }^{14}$. The high incidence of RTA observed in developing countries is probably due to the lack of strict traffic rules and regulations, bad conditions of the roads, and noncompliance with the existing laws. On the contrary, other countries got lower incidence of RTA, like $31 \%$ in USA ${ }^{15}, 28 \%$ in Caracas ${ }^{9}, 29.2 \%$ in China ${ }^{11}, 26 \%$ in Canada ${ }^{16}$ and $29.8 \%$ in Japan ${ }^{17}$. This may be explained by a combination of factors that include better road conditions, better car safety features such as airbags, increased traffic control by police and the introduction of laws related to driving under drugs influence, speed limits, and seat belts.
To avoid this in Egypt; rules should be more strict regarding safety measures especially among Toktok and motorcycle drivers, and road conditions should be improved.

The $2^{\text {nd }}$ leading cause of trauma was found to be Falls with $21 \%$. Other studies showed $23.7 \%$ in USA $^{15}, 18 \%$ in Canada ${ }^{16}, 37 \%$ in Japan ${ }^{17}$ and $31.6 \%$ in China ${ }^{11}$. Most of the cases of this study were at children and younger age group; perhaps due to the increased number of children escaping school by jumping over the wall, but the number may be misleading since some patients claim the reason is fall to avoid troubles while the actual cause was assaults.

Seven patients had iatrogenic fracture during extraction, mainly during wisdom extraction by less trained surgeons and general practitioners. Rules should be set, and monitoring should be made by the syndicate to refrain general practitioners from performing Oral and Maxillofacial Surgery procedures requiring well-trained surgeons. On the other hand, the number reinforces the good reputation of the Oral Surgery department as a reliable referral location.

Although Cairo is not considered a rural area, seven of the patients had a fracture due to animal hits and bites, mainly horses and donkeys; this can be explained by the fact that horse and donkey driven carriages are still present in Town in spite of the rules refraining them. On the other hand; none of the patients had sports injuries; this is an alarming fact indicating that just a few percentages of the population are practicing sports.

Sixty-four percent of the population of this study had more than one fracture site; this is similar to the findings of Ogundare et al ${ }^{18}(52.25 \%)$ and many others as $56.4 \%$ in China ${ }^{11}$ and $60 \%$ in Canada ${ }^{16}$. The fact that Multiple mandibular fractures represented almost half of the injuries encourage the surgeons to always look for other indirect fracture 
locations often missed during diagnosis, namely subcondylar and angle fractures of the opposite side.

The findings of this study shows a relatively low percentage of midface and upper face fracture; ZMC fractures were only $8.2 \%$, Le Fort $4.1 \%$, orbital floor fractures $2.9 \%$ and zygomatic arch $1.75 \%$; this may be explained by the fact that these fractures are treated mainly at other departments of El-Kasr El-Ainy as orthopedics, plastic surgery, and ENT. This conflict should be solved by setting more rules regarding different departments' specialties, and the development of a trauma center combining different specialties for better patient care.

The most common fracture sites found in this study was parasymphyseal $32.2 \%$, followed by mandibular angle $17.6 \%$, subcondylar $16.7 \%$ and mandibular body fractures $16.4 \%$. While the condyle was the most common fracture site in Japan ${ }^{17}$, Switzerland ${ }^{10}$ Turkey ${ }^{21,22}$ and Taiwan ${ }^{12}$, Symphyseal and Parasymphyseal were the most common in China ${ }^{11}$, Canada ${ }^{16}$, Venezuela ${ }^{9}$ and India $13,14,19,20$.

This group tried to relate the etiology of fracture and pattern represented by its location; we found that most of the RTA lead to Parasymphysial fractures, followed by angle fracture, then body and sub condylar with close percentage, then upper face fractures. While falls lead mostly to Parasymphysial fractures, then sub condylar and body fractures, and rarely to other types of fractures. Assaults lead mainly to Parasymphysial and body fractures, angle, sub condylar and ZMC fractures, and least likely to cause other types. Ghodke et al ${ }^{20}$ found that RTA causes mainly parasymphysis/ condylar fractures, and falls cause body/condyle fractures, while interpersonal violence cause angle/ parasymphyseal fractures. These findings are helpful for oral \& maxillofacial surgeon OMFS to suspect these locations after revealing the mechanism of injury.

Conflict of Interest: None.

\section{REFERENCES}

1. Kelly DE, Harrigan WF: A survey of facial fractures: Bellevue Hospital, 1948-1974. J Oral Surg 33:146, 1975.

2. Erol B, Tanrikulu R, Gorgun B: Maxillofacial fractures. Analysis of demographic distribution and treatment in 2901 patients (25-year experience). J Craniomaxillofac Surg 32:308, 2004.

3. Amr Mabrouk, Hesham Helal, Abdel Rahman Mohamed, Nada Mahmoud: Incidence, Etiology, and Patterns of Maxillofacial Fractures in Ain-Shams University, Cairo, Egypt: A 4-Year Retrospective Study. Craniomaxillofac Trauma Reconstruction 7:224-232, 2014.

4. Lydia N. Melek, Ahmed A. Sharara: Retrospective study of maxillofacial trauma in Alexandria University: Analysis of 177 cases. Tanta Dental Journal DOI: 10.4103/16878574.186943, 2016.

5. Ghada Amin Khalifa, Naglaa Shawki El-Kilani, Tamer Ahmed Nasr: Clinical outcomes of Pediatric Maxillofacial Fractures Management in Three Hospital Series in Egypt. ajoms, DOI: 10.1016/j. June 2017.

6. Tarek Elsayed Ftohy Abdelrahman, Ahmed Abdelmaboud, Ahmed Hamody: Challenge and management outcome of panfacial fractures in Sohag University hospital, Egypt. Int Surg J. 5(1):126-131, Jan 2018.

7. Chrcanovic BR: Factors influencing the incidence of maxillofacial fractures. Oral Maxillofac Surg.16(1):3-17, Mar 2012.

8. Teoman ESKITAŞCIOĞLU, Irfan ÖZYAZGAN, Atilla ÇORUH, Galip Kemali GÜNAY, Yalçın YONTAR, Mehmet ALTIPARMAK: Fractures of the mandible: a 20year retrospective analysis of 753 patients. Trkish Journal of Trauma \& Emergency Surgery; 19 (4):348-356, 2013.

9. Amarista Rojas FJ, Bordoy Soto MA, Cachazo M, Dopazo JR, Vélez H. The epidemiology of mandibular fractures in Caracas, Venezuela: Incidence and its combination patterns. Dent Traumatol.;33:427-432, 2017.

10. Zix Juergen Andreas, Schaller Benoit, Lieger Olivier, Saulacic Nikola, Thorén Hanna, Iizuka Tateyuki: Incidence, aetiology and pattern of mandibular fractures in central Switzerland. doi:10.4414/smw.2011.13207

11. Bassam M.Abotaleb, Essam Al-Moraissi, Wang Zhiqiang, Chen Ping, Kang Yongjie, Khaled Alkebsi, Yang Lan: A detailed analysis of mandibular fractures epidemiology, treatment and outcomes: A 5-year retrospective study, 
Gansu Province-China. J Oral Maxillofac Surg Med Pathol; https://doi.org/10.1016/j.ajoms.2017.12.001 2212$5558 /$ C 2018.

12. Fu-Yu Lin, Chao-I Wu, Hsu-Tang Cheng: Mandibular Fracture Patterns at a Medical Center in Central Taiwan A 3-Year Epidemiological Review. Medicine 96:51, 2017.

13. Rajanikanth K,.R..M. Borle, Nitin Bhola, Shivam: The pattern of maxillofacial fractures in central India A Unicentric retrospective study. Journal of Dental and Medical Sciences Volume 13 (1): 28-31, Feb. 2014.

14. Kolli Yada Giri, Aishwarya Pratap Singh, Ramakant Dandriyal, Niranjanaprasad Indra, Sanjay Rastogi, Sunil Kumar Mall, Shouvik Chowdhury, Himanshu Pratap Singh: Incidence and pattern of mandibular fractures in Rohilkhand region, Uttar Pradesh state, India: A retrospective study. $\mathrm{j}$ of Oral Biology and craniofacial research; $140-145,2015$.

15. Paul N. Afrooz, Michael R. Bykowski, Isaac B. James, Lily N. Daniali, and Julio A. Clavijo-Alvarez: The Epidemiology of Mandibular Fractures in the United States, Part 1: A Review of 13,142 Cases from the US National Trauma Data Bank. J Oral Maxillofac Surg 73:2361-2366, 2015.

16. M Czerwinski, WL Parker, A Chehade, HB Williams: Identification of mandibular fracture epidemiology in Canada: Enhancing injury prevention and patient evaluation. Can J Plast Surg Vol 16 No 1 Spring 2008.
17. Hiroto Tatsumi, Eiji Nakatani, Takahiro Kanno, Yoshiki Nariai, Tatsuo Kagimura, Joji Sekine: Clinical Features and Treatment Modes of Mandibular Fracture at the Department of Oral and Maxillofacial Surgery, Shimane University Hospital, Japan. PLOS ONE IDOI:10.1371/ journal.pone.0136278, September 3, 2015.

18. Ogundare BO, Bonnick A, Bayley N. Pattern of mandibular fractures in an urban major trauma center. J Oral Maxillofac Surg; 61: 713-8, 2003.

19. Harshitha K.R, Mallika P Reddy, Srinath: Etiology and pattern of mandibular fracture in and around Kolar: A retrospective study. International Journal of Applied Research; 2(4): 562-565, 2016.

20. Ghodke MH, Bhoyar SC, Shah SV. Prevalence of mandibular fractures reported at C.S.M.S.S Dental College, Aurangabad from February 2008 to September 2009. J Int Soc Prevent Community Dent; 3: 51-8, 2013.

21. Cihan Bereket, Ismail Şener, Erman Şenel, Nilüfer Özkan, Nergiz Yilmaz: Incidence of mandibular fractures in black sea region of Turkey J Clin Exp Dent.; 7(3): e410-3, 2015.

22. Teoman ESKITAŞCIOĞLU, Irfan ÖZYAZGAN, Atilla ÇORUH, Galip Kemali GÜNAY, Yalçın YONTAR, Mehmet ALTIPARMAK: Fractures of the mandible: a 20year retrospective analysis of 753 patients. Trkish Journal of Trauma \& Emergency Surgery; 19 (4): 348-356, 2013. 